\title{
Preliminary Concepts: Safeguards for Spent Light-Water Reactor Fuels
}

\section{MASTER}

$\frac{\pi}{\circ}$

4

$\frac{2}{0}$

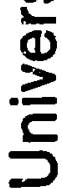

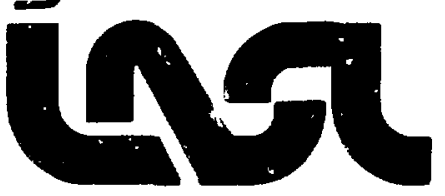




\section{Preliminary Concepts: Safeguards for Spent Light-Water Reactor Fuels}

D. D. Cobb

H. A. Dayem

R. J. Dietz

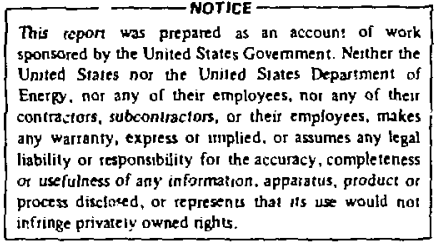




\section{EXECUTIVE SUMMARY}

This study of spent nuclear fuels is one of a series of safeguards systems studies undertaken by the L_os Alamos Scientific Laboratory (LASL) for the US Department of Energy-Office of Safeguards and Security (DOE-OSS). The series is intended to develop advanced concepts for nuclear materials management in selected types of nuclear facilities and to help guide safeguards research and development activities sponsored by DOE-OSS. Previous studies have addressed chemical separations, 1 conversion of plutonium nitrate to plutonium oxide, ${ }^{2}$ coconversion of mixed uranium-plutonium nitrate to mixed oxide, ${ }^{3}$ mixed-oxide fuel refabrication, ${ }^{4}$ and verification of the fuel inventory in large fast-critical facilities. 5

Current world-wide light-water-reactor ( $L W R$ ) spent fuel storage in reactor cooling ponds includes nearly 10000 metric tons of irradiated uranium, some 4000 tons of which is being stored in the United States (US). The present moratorium on reprocessing this fuel will require either additional interim on-site and away-from-reactor (AFR) storage capacity within the next five years or a corresponding reduction in nuclear generating capacity. Even with reprocessing, the rapid increase in nuclear power generation will require world-wide interim spent-fuel storage capacity of several tens of thousands of tons by 1990 . Additionally, the US has proposed to accept responsibility for indefinite storage of both domestic and a limited amount of foreign spent fuel in exchange for a one-time fee, to be negotiated. These estimates are conservative because of various limitations and anticipated delays in transportation and reprocessing. Probably most of the spent fuel ever irradiated will reside in storage ponds until the end of the twentietr. century.

This report outlines a preliminary strategy for safeguarding spent fue! in several types of at-reactor and AFR storage facilities. It considers subnational and national (international) diversion threats, but emphasizes the more difficult problem of international safeguards for this class of nuclear facility. Limitations and capabilities of the International Atomic Energy Agency (IAEA) safeguards and the current and frojected technology available to enhance these capabilities are described.

The key to efficient and adequate materials accountability in internationally safeguarded spent-fuel storage facilities is item accountability of verified fuel assemblies. Verification of fissile content is essential to protect against covert substitution and operating error. Verification, or fissile material assay, also provide the means for settling accounts and transferring responsibility (such as under the US offer) for residual fuel values, for criticality and safety, and for inventory and process control.

Sampling and inspection techniques for implementing adequate spent-fuel safeguards are currently under development along with the containment and surveillance techniques necessary to maintain the integrity and the continuity of knowledge of fuel assemblies during storage and transportation. The status of several improved verification techniques and the potential for fissile materials assay in spent fuels are revieweo, 
Recommendations are made for the continued improvement of tamper-indicating ideritification systems (sea: $:$ ) and the demonstration of improved non-destructive fissile-material assay and verification systems in operating storage facilities. The need for additional research in new, improved assay techniques is identified, and their potential impact on future, more effective safeguards is assessed.

This work will be extended in scope and detail in a future study after the design characteristics and safeguards requirements for a specific reference facility are addressed. Results from on going safeguards research and development efforts directed at improved verification, containment and surveillance will be incorporated as they isecome available. 
TABLE OF CONTENTS

$\begin{array}{ll}\text { ABSTRACT } & 1\end{array}$

I. INTRODUCTION 1

A. Scope 1

B. Background 2

C. Safeguards Rationale 4

II. CHARACTERISTICS OF LWR FUELS AND STORAGE FACILITIES 5

A. LWR Fuels 5

B. Storage Facilities 7

1. Reactor Storaje Pools 9

2. AFR Water Basin Stor age 9

3. Dry Surface Storage Facility 10

III. SAFEGUARDS FOR SPENT LWR FUEL 10

A. Reactor Storage 10

B. AFR Storage 12

C. Sampling Plan 13

IV. CONTAINMENT AND SURVEILLANCE TECHNIQUES

A. Introduction 14

B. Containment and Surveillance Techniques for Spent Fuel Storage 14

1. Ultrasonic Seals 14

2. Surveillance Monitors 15

3. Data Collection and Analysis 15

V. NDNDESTRUCTIVE MEASUREMENT TECHNIQUES 16

A. Gamma-Ray Techniques 16

1. Gamma-Ray Spectroscopy Measurements 16

2. Gross Gamma-Ray Measurements 17

B. Neutron Techniques 17

1. Passive Neutron Measurements 17

2. Active Neutron Measurements 19

3. Other Neutron Techniques 19

C. Other Measurement Techniques 20

1. Cerenkov Measurements 20

2. Reactivity Measurements 20

3. Caiorimetric Measurements 20

D. Summary 20

1. Gamma-Ray Measurements 20

2. Neutron Measurements 20

3. Other Measurement Techniques 21

VI. CONCLUSIONS AND RECOMMENDATIONS 21

A. Conclusions 21

B. Recomrnendations 22

ACKNOWLEDGMENTS

$\begin{array}{ll}\text { REFERENICES } & 23\end{array}$ 
TABLES

I. Characteristics of Large Light-Water Reactors 6

II. Characteristics of Fresh LWR Fuel Assemblies 7

III. Charac ter istics of Spent BWR Fuel Assemblies 8

IV. Characteristics of Spent PWR Fuel Assemblies 8

FIGURES

1. Cumulative quantities of discharged spent fuel and fuel expected to be reprocessed in the world, excluding Centrally Planned Economies.

2. Cumulative AFR storage requirements in the US.

3. Neutrons per second frum $238 \mathrm{Pu}, 240 \mathrm{pu}, 242 \mathrm{Cm}$, and $244 \mathrm{Cm}$ isotopes at a burnup of $26884 \mathrm{MWd} / \mathrm{MTU}$.

4. Relative fission chamber response versus burnup for five spent. BWR fuel assemblies. 


\title{
PRELIMINARY CONCEPTS: SAFEGUARDS FOR SPENT LIGHT-WATER REACTOR FUELS
}

by

D. D. Cobb, H. A. Dayem, and R. J. Dietz

\begin{abstract}
The technology available for safeguarding spent nuclear fuels from light-water power reactors is reviewed, and preliminary concepts for a spent-fuel safeguards system are presented. Essential elements of a spent-fuel safeguards system are infrequent on-site inspections, containment and surveillance systems to assure the integrity of stored fuel between inspections, and nondestructive measurements of the fuel assemblies. Key safeguards research and development activities necessary to implement such a system are identified. These activities include the development of tamper-indicating fuel-assembly identification systems and the design and development of nondestructive spent-fuel measurement systems.
\end{abstract}

\section{INTRODUCTION}

\section{A. Scope}

This paper reviews existing technology for safeguarding spent nuclear fuel from light-water power reactors (LWRs) and identifies key research and development activities needed to improve spent-fuel safeguards. Pertinent background information and the safeguards rationale for the study are presented in Secs. I.B and I.C, respectively. Characteristic features of spent-fuel stcrage facilities are summarized in Sec. II. Interim storage of spent fuel at LWRs and at away-from-reactor (AFR) facilities is considered. Permanerit di iposal of nuclear wastes and spent-fuel elements in geologic repositories is the subject of a separate LASL safeguards study for DOE-OSS. 
Preliminary concepts for safeguarding spent LWR fuel are presented in Sec. III. The concepts are preliminary for two reasons. First, detailed diversion scenarios and safeguards requirements have yet to be analyzed in terms of the design and operating features of specific spent-fuel handling and storage facilities. Second, certain safeguards research and development activities, especially the development of nondestructivemeasurement and fuel-assembly-identification systems, are not yet advanced to the point that the ultimate effectiveness and the vulnirabilities of the final sysiems can be predicted with any certainty. Thus, follow-on facility-specific studies of safeguards systems for spent LWR fuel should incorforate the results of the current research and development activities.

The status of these activities is reviewed in Secs. IV (Containment and Surveillance Techniques) and $V$ (Nondestructive Verification Techniques). Section IV is a summary of recent work at Sandia Laboratories, Albuquerque (SLA) to develop containment and surveillance systems for spent-fuel storage facilities. Section $V$ is a review of on-going LASL efforts to develop nondestructive spent-fuel measurement systems. The conclusions of this preliminary study and the recommendations for follow-on work are given in Sec. VI.

\section{B. Background}

At present, spent fuel discharged from LWRs is usually stored in on-site cooling ponds. The cooling time of much of this spent fuel now far exceeds the year or so originally envisioned for interim storage. Limitations of on-site storage capacity and delays in the startup of reprocessing will require an autlet for spent fuel in the next five years or so, or utilities will face a corresponding reduction in generating capacity.

Figure 1, taken from the International Atomic Energy Agency (IAEA) study of regional fuel cycle canters, ${ }^{6}$ illustrates the world-wide need for additional spent-fuel storage capacity, based on estimates of the spent-fuel discharge rates from power reactors and the projected reprocessing capacity. Cumulative amounts of stored and reprocessed spent fuel are shown in thousands of zetric tors of uranium (1000 MTU). Note that the projected world-wide reprocessing capacity will not reduce the backlog of spent fuel in storage before 1990.

In October 1977, the US Government announced its Spent Fuel Policy under which the US DOE would accept title and possession of domestic and a limited amount of foreign spent fuel in return for the payment of a one-time storage and disposal fee. The most recent published DOE projections ${ }^{7}$ (December 1978) indicate that approximately 4000 MTU of spent fuel currently reside in US reactor basins and thai 
this amount will increase to more than 25000 MTU by 1988, primarily from reactors already in operation Equivalent amounts of spent fuel will be stored in foreign reactor basins.

Figure 2 shows the current DOE projection ${ }^{7}$ of the AFR storage capacity required to meet near-term US needs. There are large uncertainties in the projected AFR storage requirements, primarily because of uncertainties in the projected expansion of at-reactor storage capacities by the utilities. The base-case DOE projection incorporates the most recent utility expansion plans. In all cases, it is assumed that a full-core storage-capacity reserve will be maintained at each reactor and that each utility wil! transship spent fuel between its own reactor basins.

Current projections of the required near-term AFR storage capacity may be optimistically low for several reasons. World-wide delays in the startup of reprocessing

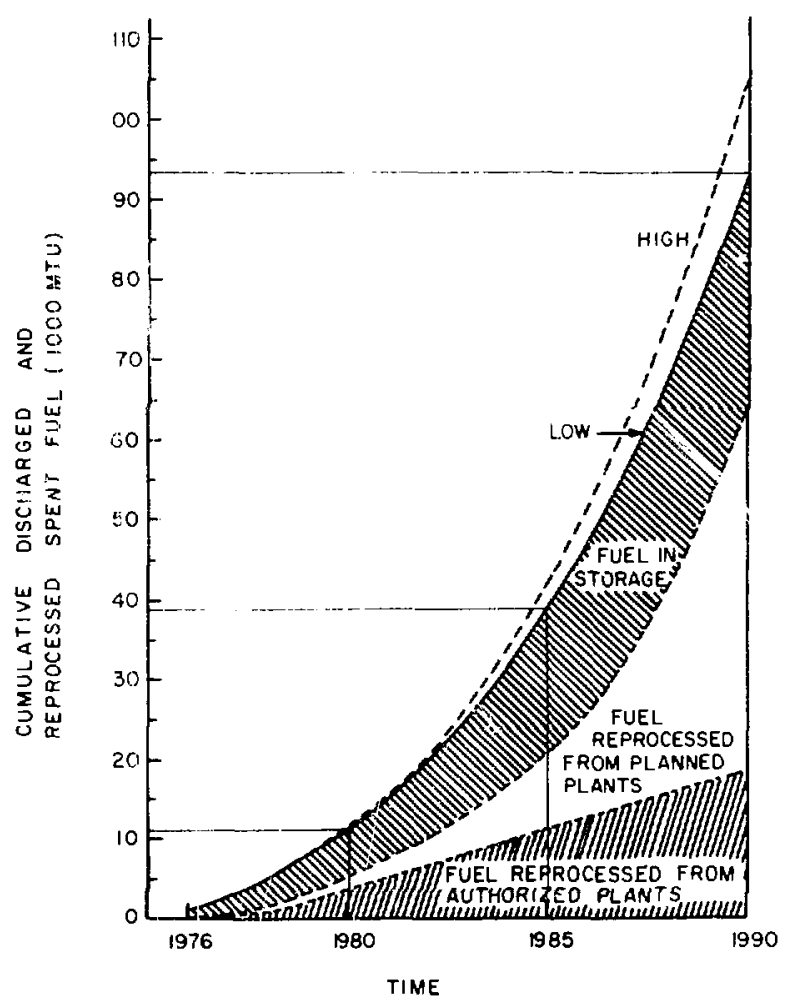

Fig. 1.

Cumulative quantities of discharged spent fuel and fuel expected to be reprocessed in the world, excluding Centrally Planned Economies. (Taken from Ref. 6).

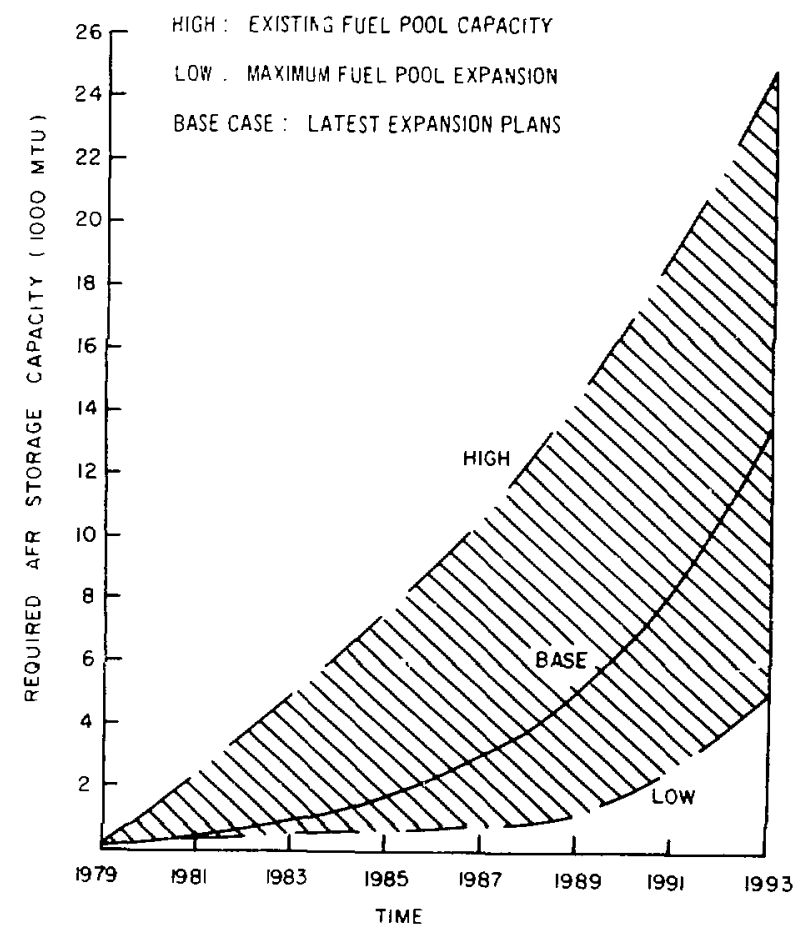

Fig. 2. Cumulative AFR storage requirements in the US. (Taken from Ref. 7). 
are continuing. Utility transshipment and expansion plans may be delayed or modified because of political, legal, and economic constraints. Any delays in the startup of AFRs will also require increased initial capacity. The currently available capacity of shipping casks to transport spent fuel within the US is only about 700 MTU per year, and the overseas transportation capacity is also severely limited. The near-term prospect for storing spent fuel in geologic repositories is not promising. For these raasons, it is necessary to conclude that most spent fuel, both domestic and foreign, will continue to be stored at reactor sites.

C. Safeguards Rationale

A comprehensive safeguards strategy for spent fuel must consider at-reactor and AFR or reprocessing-plant storage, as we:l as transportation between the storage sites. The threats to be safeguarded against mist be segregated into subnational (theft, sabotage, and other terrorise activities) and national (covert diversion or open seizure of facilities or materials by a state, presumably with the intent of producıng nuclear weapons).

Theft and terrorism are the subject of domestic safeguards systems. Terrorisi activities directed at spent fuel either in storage or in transit are considered to be extremely unlikely because of the intense self-protecting radiation fields* and the massive shielding and containment used for these materials. ${ }^{8}$ Furthermore, it is not credible that a subnational group could recover the plutonium from spent fuel for the purpose of manufacturing a nuclear explosi se device.

In the unlikely event of terrorist activities directed at spent fuel, the potential biological and environmental consequences are predictably low, ${ }^{8}$ and are substantially less than, for example, similar acts directed at a power reactor. Thus, physical security requirements for AFRs may be somewhat less stringent than those presently maintained for reactors. The main concern is the possibility of terrorist activities directed at spent fuel in transit. ${ }^{8}$ However, programs to develop protection systems for spent-fuel transportation have been active for several years in the United States and Europe. Thus, the subnational threat appears to be minimal, and adequate security and physical protection appear to be within the capability of present technology.

\footnotetext{
*It should be noted, however, that the self-protecting radiation drops to innocuous levels after a few hundred years, which is a matter of some concern when contemplating permanent storage of spent fuel.
} 
This paper focuses on the national threat and the appropriate international safeguards measures. Large quantities of spent fuel stored at dispersed reactor sites for long periods may be a potential proiiferation hazard because a nonweapons state having some reprocessing capability might eventually regard its spent fuel as a source of plutonium for nuclear weapons. Moreover, the complexity of the facilities required for reprocessing is reduced substantially as the cooling time of the sperit fuel becomes long. This is true not only because the gross activity decreases but also because the fission products (ruthenium, zirconium, and niobium) that are the most difficult to separate will eventually decay.

When considering enhanced international safeguards measures for spent fuel, it is essential to keep in mind the inherent political and legal limitations of IAEA safeguards and the practical limitation in available manpower and resources when compared to the large number of power reactors and the large quantities of spent fuel to be safeguarded. Fuel assemblies, appropriately, are treated by item accountability under current IAEA safeguards practice. Problems arise in maintaining the identity, and thereby "the continuity of knowledge", 9 of fuel assemblies from manufacturing through reactor irradiation to storage and in verifying the ${ }^{235} \mathrm{U}$ enrichment of fresh fuel and the piutonium and residual ${ }^{235} \cup$ contents of spent fuel. Thus, the two related safeguards problems of fuel-assembly identification and fissile-content verification should he addres -ef by relatively simple, low-cost inspection equipment and procedures that do not substantially increase the inspection effort.

\section{CHARACTERISTICS OF LWR FUELS AND STORAGE FACILITIES}

\section{A. LWR Fuels}

Tables I and II, taken from Ref. 10, show typical characteristics of modern LWRs and their fresh fuel assemblies. On the average, approximately one-third of the fuei in a LWR is replaced every 12 to 18 months. Refueling normaily is scheduled during periods of reduced load, usually in the spring or fall. The shutdown period scheduled for each refueling is usually three to six weeks.

Tables III and IV, derived fromi Ref. 10, show the characteristics of BWR and PWR spent fuel assemblies. The quantity of residual ${ }^{235} \mathrm{U}$ in spent $L W R$ fuel is 0.8 to $1.0 \%$ of the total uranium, and the quantity of plutonium is approximately the same. 
The present world-wide quantities of ${ }^{235} \mathrm{~J}$ and plutonium in stored spent LWR fuel are roughly 60-80 tons each. After reprocessing, the uranium requires erisichment or blending with plutonium before fabrication into recycle LWR fuel. The recovered plutonium can be used directly in mixed-oxide fuels for fast reactors or LWRs. For use as weapons materials, the uranium would have to be highly enriched, similar to natural uranium. The plutanium could be used directly after conversion to metal, although the isotopic composition is far from ideal.

TABLE I

CHARACTERISTICS OF LARGE LIGHT-WATER REACTORS

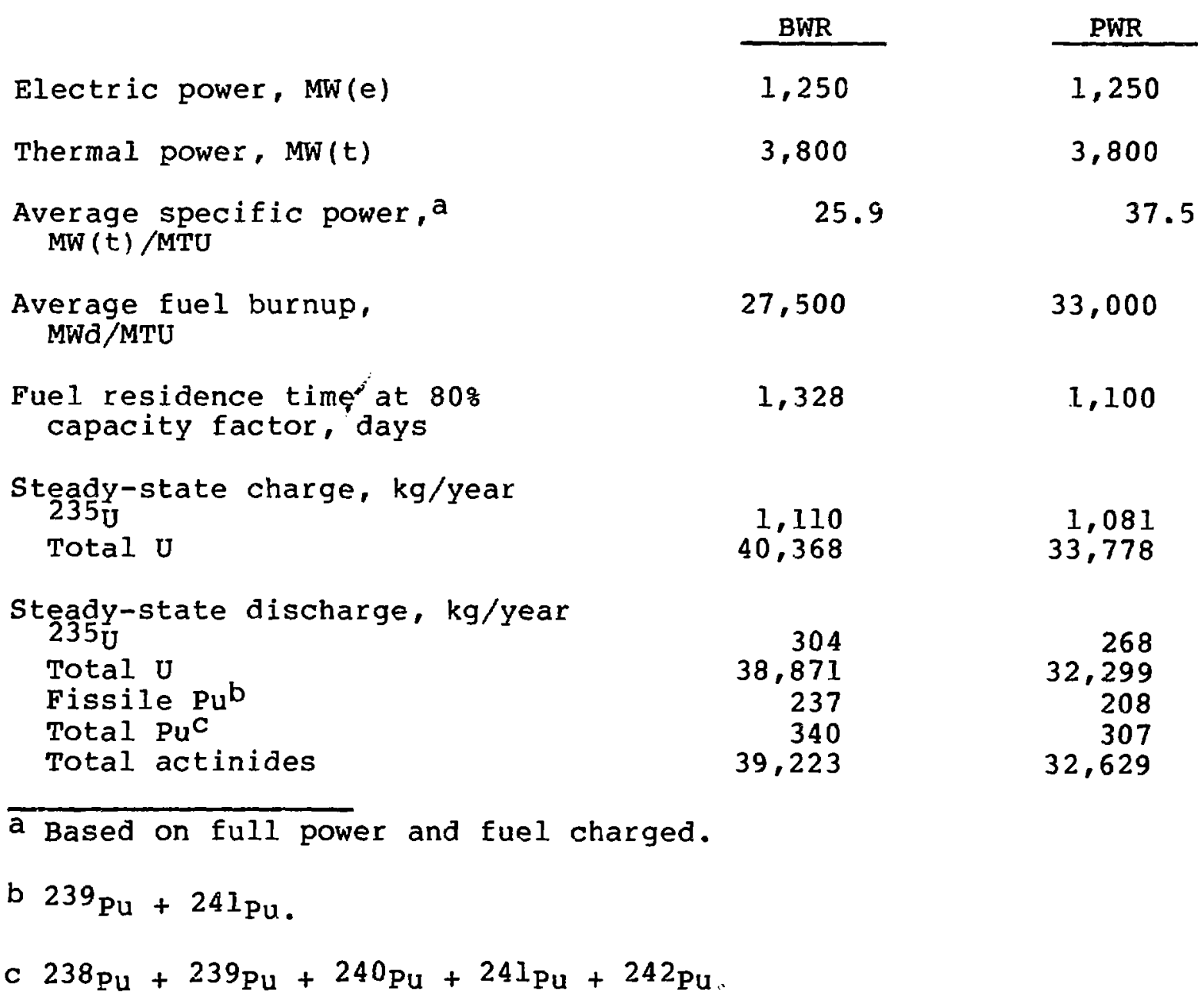




\section{B. Storage Facilities}

Types of facilities considered for interim storage of spent fuel are storage pools at reactor sites, AFR water basins, and dry surface storage facilities (DSSFs). ${ }^{8,11}$ Storage pools at reprocessing plants are similar to, but larger than, those at reactors and include equipment for transferring spent fuel assemblies to the head-end process area. I

\section{TABLE II}

CHARACTERISTICS OF FRESH LWR FUEL ASSEMBLIES

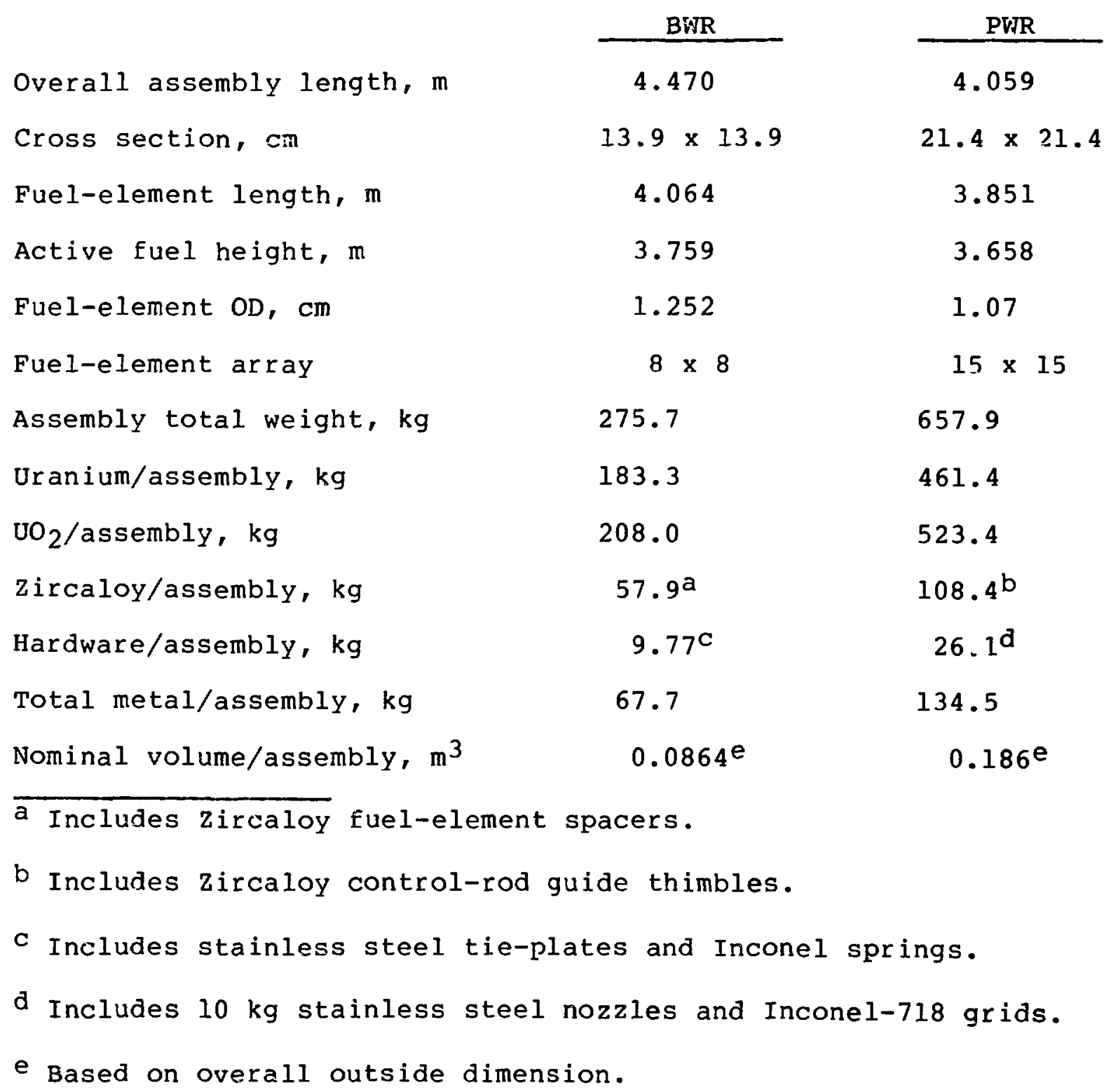


TABLE III

CHARACTERISTICS OF SPENT BWR FUEL ASSEMBLIESA

\begin{tabular}{|c|c|c|c|c|c|}
\hline & \multicolumn{3}{|c|}{ Time After Discharge from } & \multicolumn{2}{|c|}{ Reactor (years) } \\
\hline & 0 & 1 & 2 & 5 & 10 \\
\hline Uranium; $\mathrm{kg}$ & $1.77+2 b$ & $1.77+2$ & $1.77+2$ & $1.77+2$ & $1.77+2$ \\
\hline Plutonium, $\mathrm{kg}$ & $1.55+0$ & $1.55+0$ & $1.54+0$ & $1.52+0$ & $1.48+0$ \\
\hline Activity, Ci & $2.56+7$ & $3.40+5$ & $1.94+5$ & $8.67+4$ & $6.05+4$ \\
\hline Thermal, $\mathrm{W}$ & $2.49+5$ & $1.41+3$ & $7.37+2$ & $2.60+2$ & $1.67+2$ \\
\hline$\overline{a 27500 \mathrm{MWd}}$ & & & & & \\
\hline
\end{tabular}

TABLE IV

CHARACTERISTICS OF SPENT PWR FUEL ASSEMBLIESa

Time After Discharge from Reactor (years)

\begin{tabular}{|c|c|c|c|c|c|}
\hline & 0 & 1 & 2 & 5 & 10 \\
\hline Uranium, $\mathrm{kg}$ & $4.41+2^{b}$ & $4.41+2$ & $4.41+2$ & $4.41+2$ & $4.41+2$ \\
\hline Plutonium, $\mathrm{kg}$ & $4.19+0$ & $4.21+0$ & $4.18+0$ & $4.11+0$ & $4.02+0$ \\
\hline Activity, Ci & $9.25+7$ & $1.13+6$ & $6.28+5$ & $2.67+5$ & $1.82+5$ \\
\hline Thermal, $\mathrm{W}$ & $9.08+5$ & $4.81+3$ & $2.49+3$ & $8.49+2$ & $5.25+2$ \\
\hline
\end{tabular}

a $33000 \mathrm{MWd} / \mathrm{MTU}$.

b Read " $4.41 \times 10^{2}$." 
The capacity of reactor storage pools limits the maximum cooling time to approximately 5 years, or to about 10 years if the storage racks can be modified for high-density packing of the spent fuel assemblies. It is desirable to maintain a full-core reserve capacity at all times, and there is a considerable variation in fuel-pool capacities, depending on the age and size of the reactor. Conceptual designs of AFRs and DSSFs envision interim storage for perhaps 10 to as much as 100 years. ${ }^{8,11}$ Long-term (permanent) storage of spent fuel in geologic repositories is also being considered.

Spent-fuel storage facilities and operations are described in Refs. 8 arid 11 and the references therein. Here, we give an abbreviated description of each type of interim storage facility.

1. Reactor Storage Pools. Fuel storage and handling facilities for PWRs and BWRs include a fresh-fuel receiving and storage area, a spent-fuel storage pool, a refueling pool and transfer system, and a cask loading area.

A typical storage pool is $6 \mathrm{~m}$ wide by $12 \mathrm{~m}$ long by $13 \mathrm{~m}$ deep. The walls and floor are of reinforced concrete with a stainless steel liner. A shielding depth of $7 \mathrm{~m}$ of water is maintained during storage, with a minimum depth of $3 \mathrm{~m}$ during handling operations. Spent-fuel storage racks are anchored to the pool floor and are arranged in a subcritical geometry. The capacity of BWR storage pools is typically 800 to 1000 assemblies, while the capacity of PWR storage pools is typically 250 to 350 assemblies. If fully loaded, storage pools would contain approximately $1000-1500 \mathrm{~kg}$ of plutonium in sper,t fuel, or roughly double these amounts if high-density storage is used.

The storage pool is connected by an underwater gate to a loading pool in the cask loading area. Casks for road transport hold one PWR or two BWR assemblies. Casks for rail transport hold 7-12 PWR or 18-32 BWR assemblies.

The storage pool is connected by a transfer tube to a refueling pool. During refueling, spent fuel assemblies are removed from the reactor containment vessel and placed in the refueling pool. The in-core fuel assemblies are shuffled and checked ior leakage, and fresh fuel assemblies are loaded. Spent assemblies in the refueling pool are transported through the transfer tube to the storage pool where they are placed in the storage racks.

2. AFR Water Basin Storage. Conceptual AFR storage facilities include a receiving and unloading area for shipping casks from rail or road transport, fuel-assembly preparation and transfer equipment for spent LWR fuel, and storage pools and associated handling equipment. 
Shipping casks are unloaded in cask unloading pools. Preparation of the assemblies for storage may include checking for leakers and canning them, and inserting the assemblies into storage baskets for transfer to the water basin.

After preparation, storage baskets containing the spent fuel are transported to the water basin. Design concepts for a "storage farm" include appropriately sized modular storage pools. The storage baskets are clamped to fixtures in the pool and/or to each other. Transfer canals and underwater aisles are maintained to facilitate rearranging the storage baskets. The pool modules are normally isolated from each other, but provision is made for transferring storage baskets through gates between the pools.

One proposed design alternative is to dismantle the spent fuel assemblies and pack the rods into sealed canisters (perhaps two assemblies per canister) prior to storage. This procedure could effectively double the capacity of existing storage facilities.

3. Dry Surface Storage Facility. Several concepts for dry surface storage of spent fucl have been proposed. The sealed storage cask concept for long-term storage is described in Ref. 11.

Provision is made at the DSSF for disassembling and canning the spent fuel, if necessary. All operations are performed in hot cells; that is, no water shielding is used. The fuel assemblies are removed from shipping casks and are placed in sealed stainless stee! canisters, either directly or after disassembly. The canisters may then be placed in a hermetically sealed stainless steel overpack. For storage periods up to 100 years or more, the canister and overpack may be sealed in a massive carbon steel storage cask. The storage cask is then inserted into a concrete shielding silo that is placed on a concrete pad.

\section{SAFEGUARDS FOR SPENT LWR FUEL}

\section{A. Reactor Storage}

Reprocessing plants and AFR storage facilities will eventually reduce the spent fuel inventory riaintained at the dispersed reactor sites. However, for the near term, significant quantities of spent LWR fuel will continue to be stored in reactor pools, and reactor storage will continue to be the more sensitive area for the application of sa feguards.

It is appropriate to consider the problem of safeguarding spent LWR fuel in terms of item accounting of the fuel assemblies. The IAEA considers $8 \mathrm{~kg}$ of plutonium to be the 
quantity of safeguards significance, with a desired detection probability of $95 \%$ and a desired detection time of a few months for irradiated material. ${ }^{12}$ Two spent PWR assemblies or five spent BWR assemblies contain approximately one significant quantity of plutoniurn. The Agency's safeguards system should have adequate capability to Jetect the covert diversion of spent fuei and thereby also be abie to detect overt diversion (seizure).

Current IAEA inspection practice at LWRs includes item accountability for the fuel assernblies with on-site inspections, at least during normal shutdown periods for refueling, and unattended surveillance of the storage pool using cameras between inspections. The inspector uses binoculars to piece count and to check the fabrication serial number on spent fuel assemblies in the reactor storage pool. The maximum permitted routine inspection effort is one-sixth man-year per reactor. 9 The effort expended in practice generally is much less.

The safeguards approach taken by the IAEA for power reactors appears to be appropriate, but certain problems are encountered in practice. Some problems such as camerc failure between inspections can be remedied with more and better surveillance equipment. More significant are the problems of maintaining knowledge of the integrity of the fuel assemblies from fabrication through irradiation to storage and of verifying the plutonium and ${ }^{235} \cup$ contenıs.

The containment and surveillance (C-S) concept for spent fuel storage proposed by $S L A^{13}$ is based on infrequent inspections and unattended surveillance instrumentation having local and remote read-out capabilities. Implementation of this concept could provide timely detection without increasing on-site inspection requirements. The pertinent hardware and development activities are described in Ref. 13 and are summarized in Sec. IV.

A key element of the SLA concept is the development of a unique, tamper-indicating fuel-assembly-identification system (FAID) that has long-term resistance to tampering and radiation damage. The ultrasonic "seal" developed at Ispra Laboratories (EURATOM) is currently being evaluated by SLA as part of a FAID system. Ideally, the FAID would be applied to each fresh fuel assembly at the fabrication plant and then would be monitored periodically throughout the life of the assembly. In practice, two types of FAIDs may be necessary: one for fresh fuel from fabrication to reactor charge and the other for spent fuel from reactor discharge to final disposition.

Nondestructive measurement systems art being developed at LASL to measure the passive gamma-ray and neutron signatures from spent fuel assemblies (Sec. $V$ ). If these passive signatures can be related to fuel burnup, then the inspector could use these measurements to confirm the irradiation history of the spent fuel, as declared by the 
reactor operator. If the fresh-fuel enrichment and the irradiation history are known, or if it can be assumed that the enrichment and irradiation history are "typical" of a particular class of LWRs, then the spent-fuel plutonium and residual ${ }^{235} \mathrm{U}$ contents can be inferred.

Portable instruments for nondestructive measurements of spent fuel may be available in the near future. Ideally, nondestructive measurements to confirm the burnup of discharged fuel would te made by inspectors during routine inspection visits. Some combination of passive gamma-ray and neutron signatures should be measured because a combination of signatures would be diffirult to fake. If nondestructive measurements could be made on the discharged assemblies at some point in the refueling operation, special handling and shuffling of the stored assemblies in the fuel pool would not be necessary.

It is not possible currently for IAEA inspectors to verify directly the enrichment of all fresh fuel assemblies. (Fuel fabricators do routinely verify the enrichment of fresh fuel rods using NDA techniques. ${ }^{14}$ ) If FAIDs were to be applied in the future to all fresh fuel assemblies, an IAEA inspector would presumably have to be present at the fabrication plants. Some type of confirmation of the fresh fuel enrichment might then be possible; however, continuous inspection at LWR fuel fabrication plants is not permitted by the current safeguards agreements.

\section{B. AFR Storage}

Because fuel handling and storage systems at AFRs would be similar to those at reactors, containment and surveillance systems being developed for reactors should also be applicable at AFRs (Sec. IV). Nondestructive measurement systems developed for burnup confirmation at reactors could also be applied at AFRs,

Whether the spent fuel is transferred to interim storage at an AFR or to a reprocessing plant, the ability to assay the fuel nondestructively would enhance safeguards accountability and would facilitate further disposition of the spent fuel. At present, shipper-receiver balances for transfers of spent fuel from reactor storage pools can only be closed through isotopic correlations determined after dissolution in a reprocessing plant. Furthermore, the accountability tank in a reprocessing plant currently provides the first opportunity in the LWR fuel cycle to make a direct measurement of the fissile material using isotope-dilution mass spectrometry. If spent fuel is not reprocessed, the closure of shipper-receiver balances and the determination of the plutonium and ${ }^{235} \cup$ contents would be delayed indefinitely, unless direct NDA measurements are made on the spent fuel. 
Spent-fuel NDA would require using active neutron-interrogation techniques. Neutron-interrogation systems for assaying spent LWR fuel probably would only be practical for permanent installation at AFRs and reprocessing plants, not at reactors. Active neutron systems are curreritly being developed to assay spent enriched-uranium fuels prior to reprocessing and have been considered for spent LWR fuels (Sec. V).

It seems unlikely that IAEA inspectors would field active-interrogation spent-fuel NDA systems because of their anticipated size, complexity, and cost. It may be that the safeguards and potential operational advantages to be derived from direct fissile assay measurements could encourage AFF: and reprocessing-plant operators to install and maintain such systems, if they can be developed and demonstrated. At an AFR, for example, assay measurements could help to optimize the usage of available storage space by improving criticality control and could also aid in crediting the originator with residual fuel values or in the transfer of ownership of spent fuel. At a reprocessing plant, spent-fuel assay measurements could help in criticality control and in scheduling batch reprocessing campaigns to preserve the residual uranium enrichment.

The possibility is mentioned in Sec. II.B.2 that spent fuel assemblies might be dismantled at future AFRs and the fuel rods packed in canisters for storage. In that event, the assembly identification would, of course, be lost, and an inventory identification system would have to be developed for the storage canisters.

It is possible that an active neutron-interrogation system developed to measure spent fuel rods would be more sensitive than one developed for spent fuel assemblies. Ideally, the rods would be assayed prior to packing them, in the canister, and the total fissile content of the canister would be given by the sum of the measured rod contents. An NDA system for spent fuel rods would require a high-throughput capability, similar to the NDA systems developed for frosh fuel rods. 14

\section{Sampling Plan}

If FAIDs and nondestructive spent-fuel measurements can be developed, reverification of stored spent fuel assemblies presumably would only require infrequent checks of the assembly identifications. A straightforward sampling plan could be developed and used for this purpose (Ref. 5, App. D). For example, two PWR assemblies or five BWR assemblies contain approximately one significant quantity $(8 \mathrm{~kg})$ of plutonium. An approximate formula for the detection probability provided by attribute checks is 5 


$$
\mathrm{DP}=1-(1-f)^{\mathrm{D}}
$$

where DP is the desired detection probability, $f$ is the fraction of t'ie total umber of items that must be sampled, and $D$ is the number of defective (missing or altere 1 ) items to be detected. For example, if DP is desired to be $95 \%$ and D is 2 for PWR assemblies and 5 for BWR assemblies, then the inspector would randomly sample and check the FAIDs on approximately $80 \%$ of the stored PWR assemblies and $45 \%$ of the BWR assemblies. This sampling plan is conservative in that the actual detection probability is at least $95 \%$.

\section{CONTAINMENT AND SURVEILLANCE TECHNIQUES}

\section{A. Introduction}

The purpose of containment and surveillance (C-S) is to detect the undeclared movement or alteration of nuclear material. Through a combination of seals, surveillance monitors, and inspections, the C-5 systerr can monitor areas containing measured material, such as a $\mathrm{PuO}_{2}$ storage vault, thus preserving the materials accounting data, or areas containing unmeasured materia! such as scrap storage. In any case, C-S systems are ideally suiced to areas where the material form does not change and where transfer control is based on identification and piece count of items. Therefore, spent-fuel storage pools are amenable to the application of C-S techniques.

\section{B. Containment and Surveillance Techniques for Spent Fuel Storage}

A conceptual C-S system that would detect the movement of fuel in spent-LWR-fuel storage pools has been proposed. ${ }^{13}$ The system would rely on the collection of data from C-S instrumentation with local or remote data analysis and only occasional inspection. A combination of radiation, crane, acoustic, portal, electric power, and closed-circuit television monitors would be used to detect movements of the fuel assemblies. The C-S hardware would be equipped with tamper-indicating devices.

1. Ultrasonic Seals. Ultrasonic identification and integrity devices ("seals") have been under development at the Ispra Laboratories* since $1970 .^{15-17}$ They are currently

*European Economic Communities-Joint Research Center at Ispra, Italy. 
being evaluated for possible use in a FAID system. ${ }^{13}$ An item is identified by ultrasonic signals reflected from inilusions or from randomly dispersed natural defects, such as welds. Iriegrity is maintained by rendering the device unusable when it is removed from the item to which it is attached, although the inclusions can still be read to ident ify the device after is it removed. A seal identity pattern should includs at least eight amplitude peaks. At least one million seals with random inclusions can have unique signatures. 17

Ultrasonic cap seals were in experimental use on BWR fuel bundles in the Lingen VWL Gundremmingen URB reactors. ${ }^{15}$ The cap seal was developed for spent CANDU fuel in tests at Douglas Point, Canada, and will be manufactured for use with the $600 \mathrm{MW}$ CANDU reactors. ${ }^{16}$ In soent-fuel storage pools, ultrasonic cap seals could be used to identify spent fuel assemblies and to preserve the integrity of any measurements that are made. If a transducer is permanently attached or is an integral part of the seal, then continuous identification and integrity could be maintained.

Tive long-term objective is to develop a FAID system for the lifetime of LWR fuel assemblies. The continuous integrity of any such system during reactor irradiation remains to be demonstrated.

2. Surveillance Monitors. The proposed radiation monitor consists of an array of Geiger-Mueller tubes. Unfolding techniques can be used to estimate the strength, position, and direction of travel of the source.

The crane monitor reports position, load, direction of travel, and activity. The sensors for these four functions are strain gauges.

Acoustic monitors provide an intrusion alert whenever acoustic signals within the pool are characteristic of fuel assembly movements. Methods are being developed to distinguish between fuel movements and expected background signals.

Portal monitors indicate door openings, and electric power monitors indicate the use of electric motors.

The closed-circuit television system records a TV picture at intervals determined by the inspector or when an anomalous condition is detected by the other sensors.

3. Data Collection and Analysis. Data is transmitted from each sensor through 6 tamper-indicating fiber optic system to a data collection and analysis computer. The computer provides on-site analysis and transmittal of data on command to a remote monitoring station. 


\section{NONDESTRUCTIVE MEASUREMENT TECHNIQUES}

Nondestructive measurement techniques are being developed to confirm the burnup and to verify directly the fissile contents of irradiated nuclear fuels. ${ }^{18}$ Most of these techniques rely on measurements of characteristic garnma-ray or neutron signatures. Other proposed techniques lise Cerenkov radiation, reactivity, or calorimetric measurements. All techniques require further development, and suitable field instrumentation currently is not available for any of them.

\section{A. Gamma-Ray Techniques}

Gamma-ray measurement techniques can be divided into two categories, gamma-ray spectroscopy and gross gamma-ray measurements. Such measurements potentially can be related to both cooling time and burnup after a cooling time of several months.

1. Gamma-Ray Spectroscopy Measurements. The gamma-ray spectroscopy methods that have been investigated are absolute gamma-activity measurements and gamma activity-ratio measuremunts. Both methods measure the gamma activity of selected fission products. Fuel burnup and cooling time may be inferred from these measurements.

The selection of the fission products to be measured is vital. They should have nearly equal fission yields for the major fissioning nuclides in the fuel, a low neutron-capture cross section, a relatively long half life, a low migration in the fuel, and an easily resolvable spectrum with relatively high-energy gamma rays. The fission products that satisfy most of these criteria are ${ }^{95} \mathrm{Zr},{ }^{106} \mathrm{Ru}-{ }^{106} \mathrm{Rh},{ }^{134} \mathrm{Cs},{ }^{137} \mathrm{Cs}$, ${ }^{144} \mathrm{Ce}-{ }^{144} \mathrm{Pr}$, and ${ }^{154} \mathrm{Eu}$.

Gamma-ray spectroscopy measurements generally use intrinsic germanium detectors that view a portion of the spent fuel assembly through a collimator. In order to obtain accurate measurements of burnup and cooling time by high-resolution gamma-ray spectroscopy, an axial scan of the assembly or a standard gamma-ray profile would be required.

For the absolute gamma-ray activity method, the detection efficiency must be known and the measurement geometry must be carefully controlled. For the gamma-ray activity-ratio method, only a relative detection efficiency is required, and the ratio method is less sensitive to variations in measurement geometry. These are important advantages for the activity-ratio method; however, the effective fission yields of some of the isotopes used in the activity-ratio method are not known. 
2. Gross Gamma-Ray Measurements. Gamma-ray spectrometric techniques require relatively long counting times for good statistics. A recent work ${ }^{19}$ demonstrates the use of gas chambers to provide a simple, accurate, and rapid method for measuring the axial gross gamma-ray profiles of spent fuel assemblies.

The gross gamma-ray method may have an accuracy approaching $10 \%$ for confirmation of burnup, if the cooling time is known independently. Wher used in conjunction with high-resolution gamma-ray spectroscopy, the accuracy is improved. If calibrations of the gas chamber response versus burnup for various cooling times could be determined empirically, then the gas chamber could provide a relatively simple tool for independently confirming the burnup.

\section{B. Neutron Techniques}

Neutron measurement techriques can be divided into two categories, active and passive. Active techniques involve irradiation with neutrons to produce fissions in the sample. The resuiting neutron "signals" are interpreted to determine quantitatively the amount of fissile material present. Passive techniques measure the riaturally occurring neutron radiation from the samples.

Neutron techniques potentially have some advantages over gamma-ray techniques. Neutron measurements probably could be made immediately after discharge from the reactor; gamma-ray measurements require a cooling period. Attenuation is not nearly so much of a problem for neutron techniques because neutrons have a very high penetrability relative to gamma rays in nuclear materials. In other words, neutron measurements "see" the interior rods of the fuel assembly; gamma-ray measurements do not.

Active neutron techniques might make it possible to determine directly the total fissile content and perhaps the ${ }^{235} U$ and fissile plutonium contents separately as well; one can only infer the burnup and, hence, estimate the fissile content from passive gamma-ray or neutron techniques. Moreover, active neutron measurements probably would not require an accurate measurement of cooling time; passive gamma-ray and neutron measurements would.

On the other hand, neutron techniques have some disadvantages. The presence of moderators or neutron poisons may introduce $\varepsilon$ rrors. Self-shielding corrections that are required for thermal-neutron interrogation may not be easily determined, and active neutron-interrogation systems tend to be large and are not easily transportable.

1. Passive Neutron Measurements. Neutrone from spent fuel assemblies arise from either spontaneous fission or from $(\alpha, n)$ reactions. The even isotopes of plutonium and 
curium undergo spontaneous fission. The $(\alpha, n)$ neutrons result from reactions cf alpha particles from the radioactive decay of plutonium, americium, and curium with light elements (mostly oxygen) in the matrix. The neutron yield is a function of the alpha particle energy, the $(\alpha, n)$ cross sections of the matrix elements, and the matrix configuration. In a spent fuel assembly, the neutron emission rate depends strongly on the quantity of curium present (Fig. 3). The quantity of ${ }^{242} \mathrm{Cm}$ (162.8 day half life) is particularly important for relatively short cooling times.

Recent investigations ${ }^{18,20-21}$ indicate that the total neutron emission rate is proportional to burnup at constant cooling time. Passive neutron measurements using a fission chamber are described in Ref. 20. It was found that the neutron emission rate varied approximately as the 3.4 power of the lurnup for botn PWR and BWR fuels (Fig. 4). An axial scan using the fission chamber was also compared with an axial

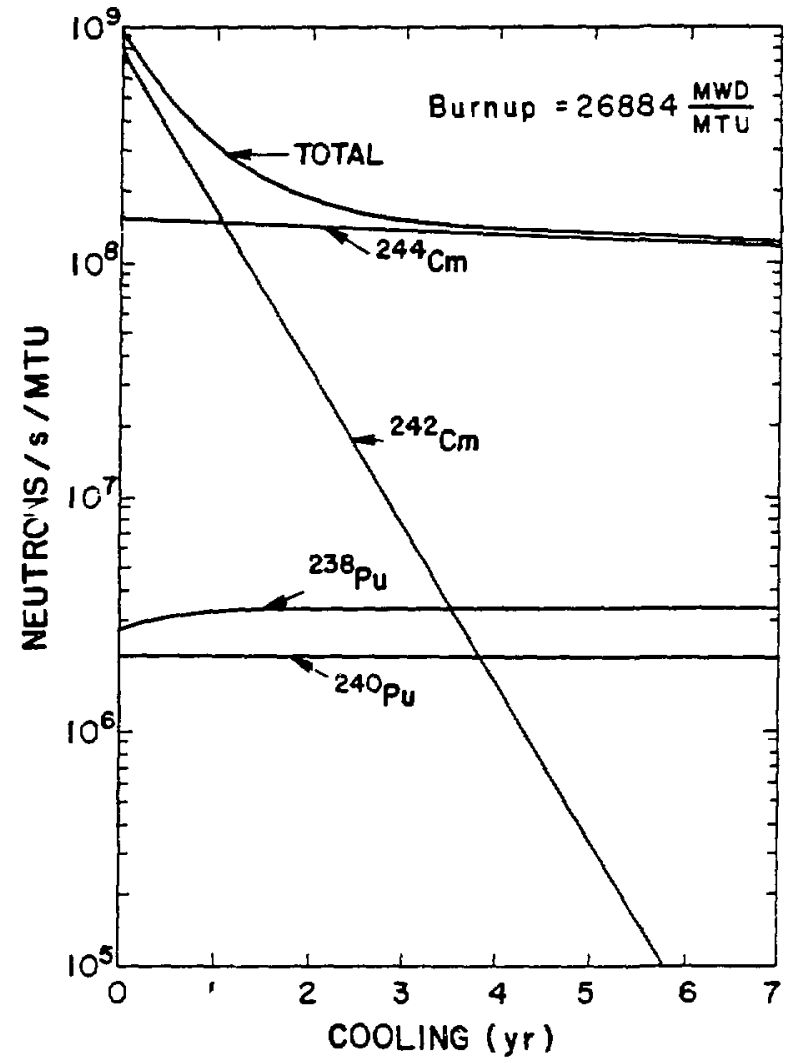

Fig. 3.

Neutrons per second from ${ }^{238} \mathrm{Pu},{ }^{240} \mathrm{Pu}$, $240 \mathrm{Cm}$, and ${ }^{244} \mathrm{Cm}$ isotopes at a burnup of $26884 \mathrm{MWd} / \mathrm{MTU}$. (Taken from Ref. 18).

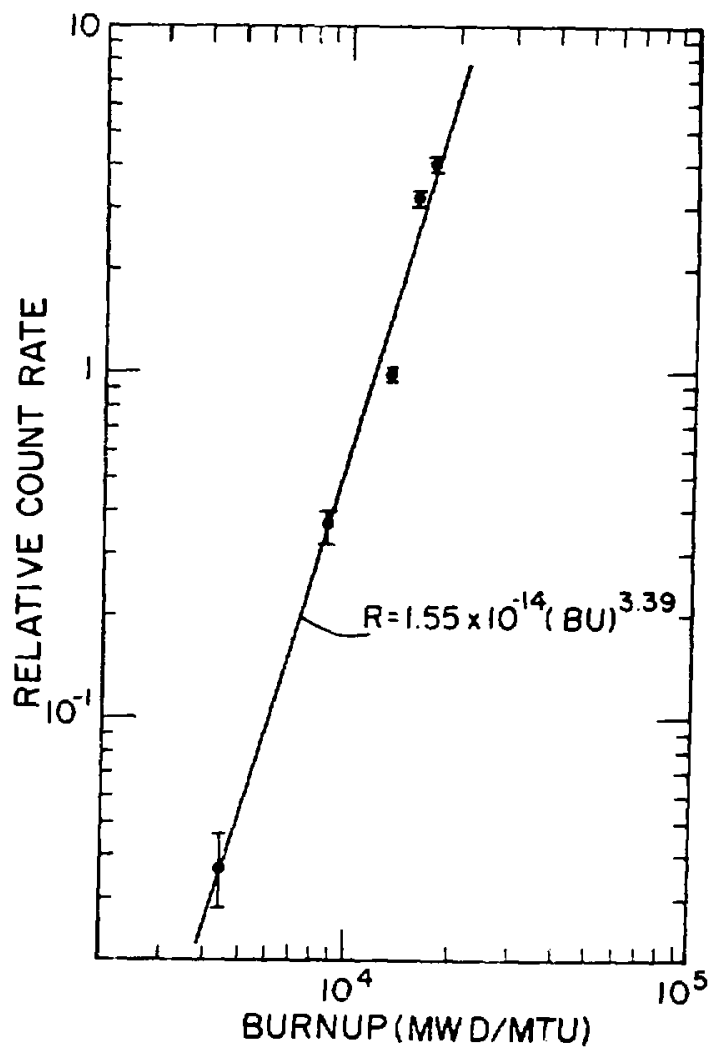

Fig. 4. Relative fission chamber response versus burnup for five spent BWR fuel assemblies. (Taken from Ref. 18). 
gamma-ray scan from an intrinsic germanium detector. Good correlation between the passive gamma-ray and neutron profiles was found.

Passive neutron measurements appear promising because a simple room-temperature detector is used, simple electronics are required, and measurement and data processing techniques are straightforward. However, the effect of cooling time on neutron signals over a wider range of burnup and the use of detectors other than fission chambers must he investigated.

2. Active Neutron Measurements. Active neutron interrogation techniques use neutrons from a radioactive source $\left({ }^{252} \mathrm{Cf}\right.$ or a gamma-induced source such as $\left.\mathrm{Sb}-\mathrm{Be}\right)$ to induce fissions in the sample. The resulting fission neutrons, both prompt and delayed, are counted to determine the total fissile content and to separate the fissile elements. Active neutron systems for spent LWR fuel have been proposed, ${ }^{18}$ and such systems appear to be feasible. Potentially, active neutron systems could provide a direct assay of the fissile plutonium and uranium contents.

3. Other Neutron Techniques. Most active neutron techniques measure the total number of neutrons emitted from the sample. Two alternative techniques are the slowing-down spectrometer (SDS) and neutron resonance absorption.

Using a SDS, the ${ }^{235} \mathrm{U}$ and ${ }^{239} \mathrm{Pu}$ contents would be separated by the differences in their cross sections at certain neutron energies. However, accuracy is lost because the l-ev resonance of the unknown amount of ${ }^{240} \mathrm{Pu}$ may overlap the 0.3 -ev ${ }^{239} \mathrm{Pu}$ resonance. Also, it is not known if the SDS could be used to measure an entire assembly because the response across the assembly would not be uniform, and consequently energy resolution would be lost.

Neutron resonance-absorption techniques potentially can determine the uranium and plutonium fissile contents using a fast chopper and a time-of-flight spectrometer. An intense epithermal neutron source is required, probably from a reactor. Aside from the rather complicated equipment, this method may not be applicable to spent fuel assemblies because interpretation of the signals can be very complicated if the sample is not in a slab geometry. 
C. Other Measurement Techniques

1. Cerenkov Measurements. The measurement of Cerenkov radiation to deduce burnup and cooling time of irradiated nuclear fuel has been proposed, ${ }^{20}$ and a preliminary feasibility study has been completed.

Cerenkov radiation is produced by the passage of high-energy charged particles through a transparent medium at a particle velocity greater than the local velocity of light in the medium. In spent fuel pools, Cerenkov radiation is produced by Compton electrons from fission-product gamma rays; hence, the Cerenkov radiation is related to the total gamma-ray activity. Work is continuing to examine possible correlations between Cerenkov radiation and burnup. ${ }^{22}$

2. Reactivity Measurements. Reactivity techniques basically measure the total "worth" of an assembly. Differentiation between uranium and plutonium could be obtained by tailoring the neutron or "adjoint" flux. Estimates indicate that such systems would be relatively accurate and relatively expensive.

3. Calorimetric Measurements. Calorimetric techniques measure the heat output from an assembly that is generated predominantly by the fission products. Calorimetric measurements require detailed irradiation and cooling histories that may or may not be available.

D. Summary

1. Gamma-Ray Measurements. Spectroscopic gamma-ray activity-ratio measurements appear especially promising for spent fuel that has been cooled for several months. Estimates of cooling time have been made from spectroscopic gamma-ray measurements with an accuracy of approximately $3 \%$. Techniques for estimating burnup from gamma-ray measurements need additional development. Accuracies in the range of $5-10 \%$ probably are attainable. Gross gamma-ray measurements employing gas chambers complement spectroscopic activity-ratio measurements.

2. Neutron Measurements. Passive neutron measurement techniques have been demonstrated and a power-law relationship between neutron count rate and burnup at a fixed cooling time has been obtained. However, more measurement experience is required 
for difrerent types of reactor fuels and over a wider range of burnup. Neutron measurements are promising bacause they are sensitive to alterations in the interior of the assemblies and probably can be made after a short cooling time.

Active neutron interrogation techniques for measuring the residual enrichment of spent enriched-uranium fuel prior to reprocessing are being developed. The goal of that program is to achieve an assay accuracy of $5 \%$ or better. Active neutron techniques also offer the pousibility of measuring directly the fissile content of spent LWR fuel and perhaps also discriminating between the fissile plutonium and uranium contents.

3. Other Measurement Techniques. More experience, particularly with Cerenkov radiation measurements, is required before the effectiveness and applicability of the other proposed techniques for spent. LWR fuel can be assessed.

\section{CONCLUSIONS AND F.ECOMMENDATIONS}

A. Conclusions

The relative invulnerability of spent-fuel storage facilities to theft or terrorism and the fact that most spent fuel will continue to be stored at widely dispersed reactor sites make safeguarding spent LWR fuel primarily a problem for the application of international safeguards. The IAEA safeguards measures for spent fuel stored at power reactors, namely item accounting of fuel assemblies, infrequent on-site inspection visits, and unattended surveillance between inspections, appear to be appropriate, but some equipment upgrading would enhance these measures.

Two key upgrades are (1) a unique, tamper-indicating fuel-assembly-identification system that can survive in-reactor irradiation, and (2) nondestructive measurement systems for confirmation of burnup, preferably portable passive gamma-ray and neutron systems for use by IAEA inspectors.

If it is not feasible to develop a FAID that can survive irradiation, an identifier might be attached to the spent fuel assemblies after discharge or the storage racks in the pool might be sealed. If confirmation of the burnup of discharged assemblies is not feasible during refueling, confirmation measurements could be made on the assemblies in storage; however, this would require shuffling the stored assemblies and retrieving them for measurement. 
Spent-fuel NDA measurements at AFRs and reprocessing plants would have important safeguards benefits. Fissile assay measurements, made when the spent fuel is received, could be used to close shipper-receiver balances and to provide a direct verification of the fissile plutonium and uranium contents. Assay measurements would also facilitate the final disposition of the spent fuel.

\section{B. Recommendations}

The following recommendations are made $\mathrm{cn}$ the basis of this preliminary study.

1. The development of unique, tamper-indicating identification systems for LWR fuel assemblies should continue. The effectiveness of proposed systems should be demonstrated, and their potential vulnerabilities should be determined.

2. The development of nondestructive measurement systems for the confirmation of burnup should continue. Portable passive neutron and gamma-ray systems for inspector use should be developed.

3. The feasibility of fissile assay of spent LWR fuel by active neutroninterrogation should be demonstrated.

4. Safeguards and aperational requirements of specific spent-fuel-storage facility designs should be analyzed.

\section{ACKNOWLEDGMENTS}

The authors are indebted to their safeguards colleagues at the Los Alamos Scientific Laboratory for providing the information on which the discussion of measurement technology is based. Drs. S. T. Hsue and J. R. Phillips deserve special mention. Several of the ideas expressed here originally came to our attention in draft working papers prepared by $E, V$. Weinstock of the Brookhaven National Laboratory. The authors esperially thank those reviewers who contributed valuable comments and suggestions on the original draft of this report: Dr. Weinstock and colleagues of Brookhaven, G. F. Molen and F. A. Shallo of Allied-General Nuclear Services, and E. E. Voiland of General Electric-Morr is. 
REFERENCES

1. E. A. Hakkila, D. D. Cobb, H. A. Dayem, R. J. Dietz, E. A. Kern, E. P. Schelonka, J. P. Shipley, D. B. Smith, R. H. Augustson, and J. W. Barnes, "Coordinated Safeguards for Materials Management in a Fuel Reprocessing Plant," Los Alamos Scientific Laboratory report LA-688I (September 1977).

2. H. A. Dayem, D. D. Cobb, R. J. Dietz, E. A. Hakkila, E. A. Kern, J. P. Shipley, D. B. Smith, and D. F. Bowersox, "Coordinated Safeguards for Materials Management in a Nitrate to Oxide Conversion Facility," Los Alamos Scientific Laboratory report LA-70ll (April 1978).

3. H. A. Dayem, D. D. Cobb, R. J. Dietz, E. A. Hakkila, E. A. Kern, E. P. Srhelonka, J. P. Shipley, D. B. Smith, "Coordinated Safeguards for Materials Management in a Uranium-Plutonium Nitrate-to-Oxide Coconversion Facility: Coprecal," Los Alamos Scientific Laboratory report LA-7321 (February 1979).

4. J. P. Shipley, D. D. Cobb, R. J. Dietz, M. L. Evans, E. P. Schelonka, D. B. Smith, and R. B. Walton, "Coordinated Safeguards for Materials Management in a Mixed-Oxide Fuel Facility," Los Alamos Scientific Laboratory report LA-6536 (February 1977).

5. D. D. Cobb, J. L. Sapir, E. A. Kern, and R. J. Dietz, "Concepts for Inventory Verification in Critical Facilities," Los Alamos Scientific Laboratory report LA-7315 (December 1978).

6. "Regional Nuclear Fuel Cycle Centres," STI/PUB/445, IAEA, Vienna (1977).

7. "Spent Fuel Storage Requirements - The Need for Away-From-Reactor Storage," US Department of Energy report DOE/E7-0075 (February 1979).

8. "Storage of US Spent Power Reactor Fuel - Draft Environmental Impact Statement," US Department of Energy report DOE/EIS-0015-D (August 1978); see also "Risks Associated with Nuclear Power: A Critical Review of the Literature," National Academy of Sciences (April 1979).

9. "The Structure and Content of Agreements Between the Agency and States Required in Connection with the Treaty on the Non-Proliferation of Nuclear Weapons," INFCIRC/153, IAEA, Vienna (June 1972).

10. C. W. Alexander, C. W. Kee, A. G. Croff, and J. O. Blomeke, "Projections of Spent Fuel to be Discharged by the US Nuclear Power Industry," Oak Ridge National Laboratory report ORNL/TM-6008 (October 1977).

11. J. W. Moyer and C. S. Sormier, "Baseline Descriptions for LWR Spent Fuel Storage, Handling, and Transpoitation," Sandia Laboratories, Albuquerque report SAND77-1953 (April 1978); see also "Alternatives for Managing Wastes from Reactors and Post-Fission: Operations in the LWR Fuel Cycle," ERCA-76-43, Vol. III (May 1976).

12. "IAEA Safeguards Technical Manual, Introduction, Part A," IAEA-174, Vienna (1976). 
13. J. P. Holmes, "Conceptcal Design of a System for Detecting National Diversion of LWR Spent Fuel," Sandia Laboratories, Albuquerque report SAND78-0192 (September 1978).

14. T. D. Reilly and M. L. Evans, "Measurement Reliability for Nuclear Material Assay," Los Alamos Scientific Labaratory report LA-6574 (January 1977).

15. S. J. Crutzen, C. J. Vinche, W. H. Burgers, M.R. Combet, "Remote Controlled and Long Distance Unique Identification of Reactor Fuel Elements or Assemblies," IAEA/SM/231-21 (October 1978).

16. S. J. Crutzen and R. G. Dennys, "Use of Ultrasonically Identified Security Seals in the 600 MW CANDU Safeguard System," IAEA/SM/231-124 (October 1978).

17. W. L. Zijp and S. J. Crutzen, "Statistical Aspects of Ultrasonic Signatures," IAEA/SM/231-22 (October 1978).

18. S. T. Hsue, T. W. Crane, W. L. Talbert, Jr., and J. C. Lee, "Nondestructive Assay Methods for Irradiated Nuclear Fuels," Los Alamos Scientific Laboratory report LA-6923 (January 1978).

19. D. M. Lee, J. R. Phillips, S. T. Hsue, K. Kaieda, J. K. Halbig, E. G. Medina, and C. R. Hatcher, "A New Approach to the Examination of LWR Irradiated Fuel Assemblies Using Simple Gas Chamber Techniques," Los Alamos Scientific Laboratory report LA-7655-MS (March 1979).

20. 5. T. Hsue, J. E. Steward, K. Kaieda, J. K. Halbig, J. R. Phillips, D. M. Lee, and C. R. Hatcher, "Passive Neutron Assay of Irradiated Nuclear Fuels," Los Alamos Scientific Laboratory report LA-7645-MS (February 1979).

21. J. R. Phillips, S. T. Hsue, K. Kaieda, D. M. Lee, J. K. Halbig, E. G. Medina, C. H. Hatcher, and T. R. Bement, "Nondestructive Determination of Burnup and Cooling Time of Irradiated Fuel Assemblies," First Annual ESARDA Meeting, Brussels, Belgium, April 25-26, 1979; to be published in the Proceedings.

22. E. J. Dowdy, "Interim Report on Irradiated Fuel Monitors: Cerenkov Detectors," Los Alamos Scientific Laboratory draft report (September 1, 1978). 